\title{
SAFEGUARDING MOTORIZED VEHICLES WITH ARM VIBRATORS USING ULTRASONIC SENSORS AND BLUETOOTH
}

\author{
Riski Ariyanto*, Rony Haendra Rahwanto Fora \\ Department of Electrical Engineering \\ University of PGRI Adi Buana Surabaya \\ *Corresponding email address: riskiariyanto115@gmail.com
}

\begin{abstract}
Safeguarding motorized vehicles with arm vibrators using ultrasonic sensors and Bluetooth is an innovation in safety systems on motorized vehicles (Motorbikes). This tool uses a proximity sensor and arm vibrator, which this tool will work if the motor vehicle (motorcycle) is too close to the object in front of it. When the sensor has detected an object, the vibrator will automatically vibrate the arm. When the vibrator vibrates, that will be a sign that the driver is too close to the vehicle in front of him, so the driver will maintain a safe distance from other vehicles in front. The objectives of this research activity include knowing the concept of developing a safety system on motorized vehicles that can prevent accidents, when motorists are negligent in controlling the speed of their vehicles on the highway.
\end{abstract}

Keywords: Bluetooth, Ultrasonic, Vibrator Arm.

\section{INTRODUCTION}

Motorized vehicles are the tools most needed as a medium of transportation. Motorized vehicles make the efficiency of time and energy because they were created to help human activities. On the other hand, motorized vehicles have a disadvantage if many motorcycle riders violate traffic signs. As a result, accidents often occur for motorists who are not compliant with the traffic rules that have been fixed, right. One of the goals that must be considered is to keep the distance between one rider and the other driver, so there is no accident. Therefore, we created a product innovation in the form of a motorized accident prevention device with an arm vibrator using ultrasonic sensors and Bluetooth. In this product innovation the driver will get a notification if the condition of the rider with the one in front is too close which will endanger the driver.

The objectives of this study are:

1. The vibrator simulation process starts from an ultrasonic sensor to keep the distance that will be sent to the vibrator to vibrate via Bluetooth.

2. can help motorists in managing security during driving activities.

3. To find out the vibrator's working ability to vibrate after receive signals from Bluetooth via ultrasonic sensors.

4. Can reduce the number of accidents that occur every year.

The components used in this study are:

\section{A. ULTRASONIC SENSOR}

Ultrasonic sensor is a component that works based on the principle of reflection of a sound wave so that it can be used to interpret the existence of a specific object in its frequency. This sensor has a frequency of around $40 \mathrm{KHz}$ to $400 \mathrm{KHz}$. Ultrasonic sensors are formed from two units, namely the transmitter unit and receiver unit. How it works ultrasonic waves emitted by the transmitter unit to the air around where he is, and if there are specific objects around the place will cause ultrasonic waves to reflect. The reflection is then received by the receiver-sensor unit. Furthermore, vibrations occur in the vibrating diaphragm which causes a piezoelectric effect. Nearly detected objects are factors that determine the magnitude of the electrical signal amplitude produced by the receiving sensor. The sensor uses reflections to calculate the distance between objects and sensors. To calculate the distance can be done by multiplying half the time the signal is emitted until the signal is received back by the sensor, 
with the propagation speed of the signal on the propagation medium (air). Lauw Lim Un Tung (2005) also explained that the working principle of ultrasonic sensors is used to measure distance. Ultrasonic pulse / signal sent from the transmitter $(40 \mathrm{KHz})$ when it hits an object, the pulse is reflected back by the ultrasonic receiver. By measuring the time interval between pulses sent and received, the distance between the measuring device and the object can be measured.

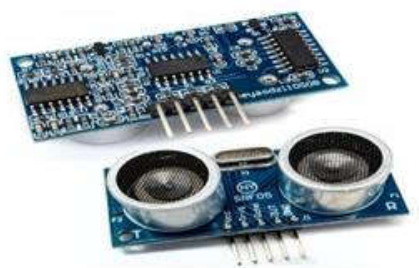

Figure 1. Ultrasonic Sensor

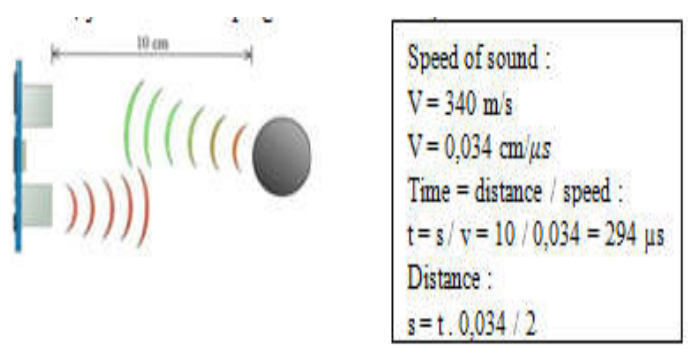

Figure 2. How the Ultrasonic Sensor works

\section{B. MICROCONTROLLER}

According to Barnet (203, P83), a microcontroller is a processor used for the sake of control. Although the shape is smaller than computers and mainframes, this tool is built from the same elements. So that it can be used for automation / computerization systems in accordance with input or programs that we input into it. Here we will use the Arduino Uno, Arduino Microcontroller Uno is a circuit board based on the ATmega328 microcontroller. This IC (integrated circuit) has 14 digital inputs / outputs (6 outputs for PWM), 6 analog inputs, $16 \mathrm{MHz}$ ceramic crystal resonator, USB connection, adapter socket, ICSP header pin, and reset button. This is what is needed to support a microcontroller easily connected with a USB power cable or AC adapter power supply cable to DC or battery.

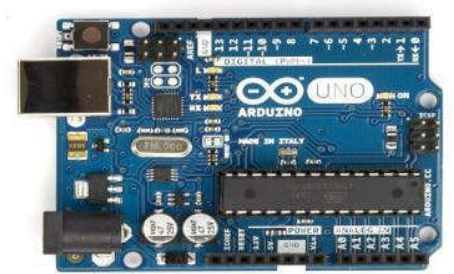

Figure 3. Arduino UNO R3 ATmega328

Uno differs from all early microcontrollers which do not use special USBto-serial FTDI driver chips instead. The application of USB-to-serial is ATmega16U2 version R2 (previous version ATmega8U2). The Arduino Uno Rev.2 version with an $8 \mathrm{U} 2$ resistor to a ground line that is more easily given to DFU mode.

\section{BLUETHOOTH}

Bluetooth is a wireless/wireless communication technology that works by sending data (Transmitter) through radio signals at certain frequencies $(2.4 \mathrm{GHz})$ and can receive data (Receiver). this tool is very suitable to replace the role of cables that require space/place.

One example of Bluetooth is the Bluetooth HC-05 Module. The HC-05 module is a Bluetooth module that can function as a master or as a slave. The HC-05 module uses a chipset made by Cambridge Silicon Radio (CSR) $\mathrm{BC} 417143$ and has been installed on the breakout board (Bambang Aji, 2012). The effective range is 10 meters, although it can reach more than 10 meters, but the quality of the connection decreases.

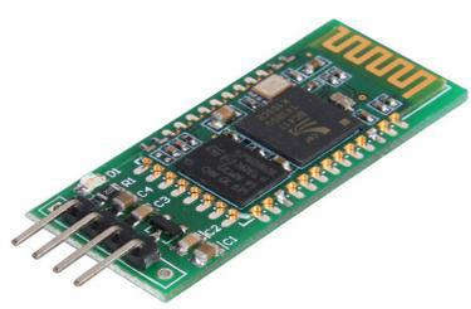

Figure 4. Bluetooth module

\section{MOTOR VIBRATOR}

Vibrator motor functions as an actuator, which can change direct current into rotary / motion / vibration torque. Motor Vibrator works based on the principle of electromagnetic force 
so that when the motor is given a power supply, the current will flow into the motor then produce a rotating / vibration torque (Ahmad Riyad F). This vibrator motor is very suitable as a sign for warning, by using the dc power supply this vibrator motor is very safe to use because the vibration effect will not harm the user.

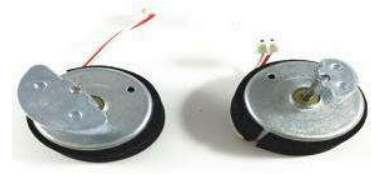

Figure 5. Motor DC

\section{E. POWER SUPPLIES / ELECTRIC RESOURCES}

The power source used is a 6-volt DC battery to turn on the Arduino and an ultrasonic sensor, and a 9-volt DC battery is used to turn on the bluetooth receiver and vibrator motor to be mounted on the arm.

How the Tool Works:

1. Ultrasonic sensors emit frequencies (transmitter sensors) then the frequency will be reflected back when it hits an object (received by the receiving sensor).

2. When the frequency is returned, we can know the distance of the object, then we can input the distance as input to the microcontroller.

3. Here we can set at what distance this tool will work, for example if the ultrasonic sensor detects an object at a distance of 5 meters then the microcontroller will work at that distance and issue a signal that will be emitted by the Bluetooth (transmitter) and will be captured by Bluetooth (receiver).

4. Then the signal is converted by Bluetooth to activate the vibrator motor.

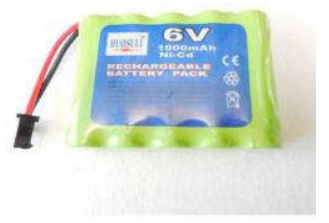

Figure 6. Battery

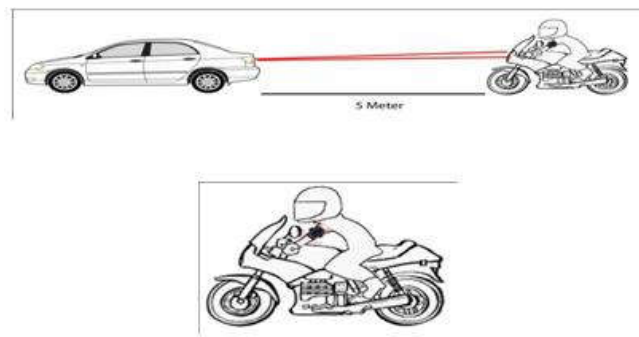

Figure 7. Schematic device

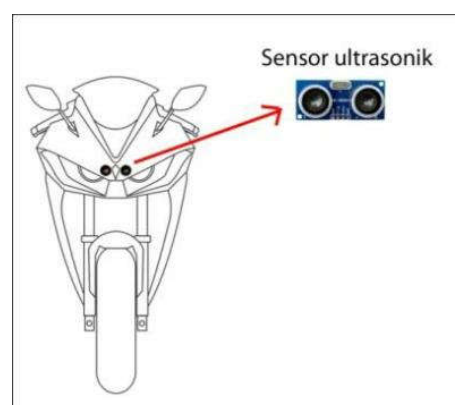

Figure 8. Position of ultrasonic

\section{RESEARCH METHODS}

The method that will be used is the experimental method. This method tests the tools and observations of the tools so that researchers can analyze the experiment tools. The testing of tools is carried out in several stages, including the gradual testing of tool components and the overall testing of tools. This test aims to determine the results of the design that has been carried out on several experiments conducted in two places, namely the Electrical Engineering laboratory of the University of Adi Buana Surabaya J1. Ahmad Yani Surabaya. Then from the test results, it will be analyzed with the data collected using discrete, discrete analysis about data from observations and vibrator measurements to remind the distance from our vehicle. After doing the next discrete analysis, it can be interesting to discuss the performance and success of motorized accident prevention devices with arm vibrators using ultrasonic sensors and Bluetooth.

The scope of this study is:

a. Ultrasonic sensors are used to detect other vehicles or objects around or close to the driver's vehicle. 
b. The set point distance in testing the system as a whole is $5 \mathrm{~m}$ with a vehicle speed of $10 \mathrm{~km}$ / h, $20 \mathrm{~km} / \mathrm{h}, 30 \mathrm{~km} / \mathrm{h}, 50 \mathrm{~km} / \mathrm{hr}$.

c. The motorcycle used in the test is a $125 \mathrm{cc}$ supra motorcycle.

d. Measurement of Bluetooth connection speed is used in using the device.

This research requires materials and tools as a series of studies as follows: Ultrasonic Sensor, Bluetooth module., Arduino Uno and Arduino Nano, Vibrator motor, Battery.

In this study there are several variables that aim to get the results achieved. These variables are:

a. Independent variables are: Distance of Ultrasonic sensor, Bluetooth speed, arm vibrator. Operational definition of variable: Distance of ultrasonic sensor is the ability to read sensors close to the distance between the driver's vehicle and the other vehicle while the Bluetooth connection speed is the intensity of the Bluetooth performance to send a signal to vibrate the arm vibrator, so the driver is cautious.

b. The dependent variable is: Motorized accident prevention device. Operational definition of variable: An accident prevention device is a device used by a driver when a motorcycle is close to another vehicle, so the device vibrates a vibrator that is mounted on the driver's arm.

Analysis of the data used is the analysis of the experimental data of the tool through the appropriate components after the measurement test. Besides that, descriptive analysis is used to describe the results of the experiment through:

1. Calculation of the ultrasonic distance needed by ultrasonic sensors to function properly.

2. Use the appropriate microcontroller, which is used as a regulator of the ultrasonic sensor voltage sensitivity.

3. Measure, look for how the fastest connectivity from Bluetooth to this tool.

4. Determine the size and weight of the tool so that it is easy to install on a motorcycle and arm.
5. Determine the appropriate battery capacity when used.

6. Determine the design of research tools to make it easier to use in motorcycle driving.

\section{RESULTS AND DISCUSSION}

Based on the results of the above data analysis, and testing carried out in two places, namely the Electrical Engineering laboratory of the University of Adi Buana Surabaya and Jl. Ahmad Yani Surabaya, the results of the component testing show that the component can work well and in accordance with the expected goals, while the overall test results show that by giving different variables. Driving safety devices cannot work properly, where Ultrasonic cannot work at a distance of more than 5 meters which is a safe distance to drive. Ultrasonic only works at effective distances of less than $5 \mathrm{~m}$ with a variety of variable speed motorbikes. But on this device Bluetooth works well even though at various motorbike speed variables.

a. The design of motorized accident prevention devices with arm vibrators using ultrasonic sensors and Bluetooth instead of cables cannot work properly and is in accordance with the expectations of driving safety. As for the results of observations as a whole the tools of the design made are:

1) All components including ultrasonic, Bluetooth, buzzer, vibrator motor work well.

2) The Bluetooth response to the device depends on distance and speed.

3) The tool will work optimally if the speed is not too high because it affects the sensor in reading distance.

b. This tool system uses Bluetooth technology, after testing 3 times the Bluetooth works well even though the motorbike's vehicle goes fast. Bluetooth can change the function of the cable with a fast connection so that it is appropriate in the installation of Bluetooth on this device.

c. Ultrasonic sensors have very little physical resistance so it is necessary to replace ultrasonic sensors with sensors that have good resistance and have a wide and stable range in the position of vibration. 
BEST

Journal of Applied Electrical, Science, \& Technology - University of PGRI Adi Buana Surabaya

p-ISSN 2715-2871

e-ISSN 2714-5247

The advantage of this tool is the use of Bluetooth is very appropriate in the function of Bluetooth as a substitute for cable. It is proven that it still works even though in the condition of variable speed motorbikes and the second Bluetooth connection after switching on it takes 8 seconds

The disadvantage of this tool is that the use of ultrasonic is still not running optimally because after testing with a variety of variables ultrasonic testing cannot read optimally when the vehicle is at high speed.

Table 1. Ultrasonic Testing Results

\begin{tabular}{|c|c|c|}
\hline experiments & Distance $(\mathrm{m})$ & LED \\
\hline 1 & 1 & On \\
\hline 2 & 1,5 & On \\
\hline 3 & 2 & On \\
\hline 4 & 2,5 & On \\
\hline 5 & 3 & On \\
\hline 6 & 3,5 & On \\
\hline 7 & 4 & On \\
\hline 8 & 4,5 & On \\
\hline 9 & 5 & On \\
\hline
\end{tabular}

Table 2. Testing Bluetooth Results

\begin{tabular}{|c|c|c|c|c|c|c|}
\hline \multirow{2}{*}{ No. } & \multirow{2}{*}{ Distance } & \multicolumn{5}{|c|}{ Sensor connection response with bluetooth } \\
\cline { 3 - 7 } & & $10 \mathrm{Km} /$ hour & $20 \mathrm{Km} /$ hour & $30 \mathrm{Km} / \mathrm{hour}$ & $40 \mathrm{Km} /$ hour & $50 \mathrm{Km} /$ hour \\
\hline 1 & $1 \mathrm{~m}$ & $1 \mathrm{Sec}$ & $1 \mathrm{Sec}$ & $1 \mathrm{Sec}$ & $1 \mathrm{Sec}$ & $1 \mathrm{Sec}$ \\
\hline 2 & $2 \mathrm{~m}$ & $1 \mathrm{Sec}$ & $1 \mathrm{Sec}$ & $1 \mathrm{Sec}$ & $1 \mathrm{Sec}$ & $2 \mathrm{Sec}$ \\
\hline 3 & $3 \mathrm{~m}$ & $1 \mathrm{Sec}$ & $1 \mathrm{Sec}$ & $1 \mathrm{Sec}$ & $2 \mathrm{Sec}$ & $3 \mathrm{Sec}$ \\
\hline 4 & $4 \mathrm{~m}$ & $1 \mathrm{Sec}$ & $1 \mathrm{Sec}$ & $2 \mathrm{Sec}$ & $3 \mathrm{Sec}$ & $5 \mathrm{Sec}$ \\
\hline 5 & $5 \mathrm{~m}$ & $1 \mathrm{Sec}$ & $1 \mathrm{Sec}$ & $3 \mathrm{Sec}$ & $3 \mathrm{Sec}$ & $5 \mathrm{Sec}$ \\
\hline
\end{tabular}

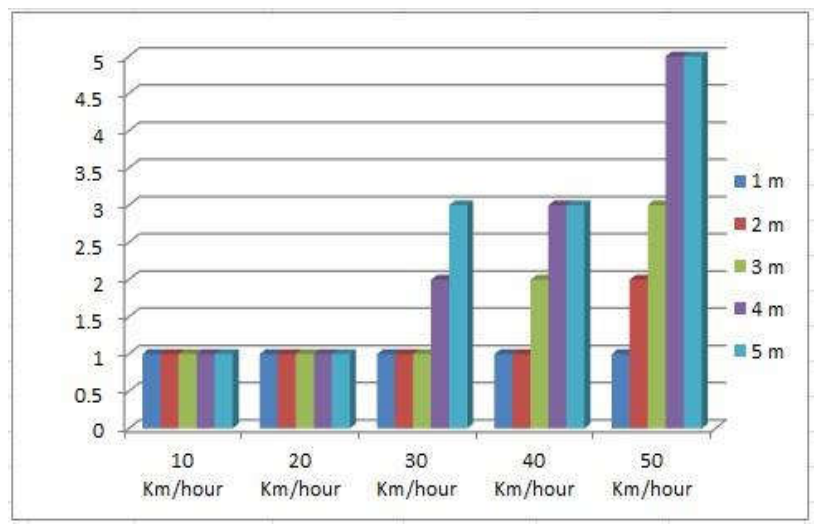

Figure 9. Graph of Bluetooth Results

\section{CONCLUSION}

From the results of the discussion on research into the design of motorized accident prevention devices with arm vibrators using Ultrasonic and Bluetooth sensors, several conclusions were obtained, including:

a. Ultrasonic sensors have physical resistance that is very less usable in the long run so it is necessary to replace infrared sensors with sensors that have good resistance and have a wide and stable range in shock or vibration conditions caused by the speed of the vehicle.

b. Sensors are needed that have strong physical resistance and have a wide range.

\section{ACKNOWLEDGMENT}

Thank you and appreciation need to be conveyed to various parties who have provided assistance in the form of guidance, direction, advice, support and convenience from the beginning to the end of this scientific article. Don't forget to say thank you to:

a. My parents are loved, thank you for your moral support and material.

b. All lecturers and staff in the Electrical Engineering Study Program and the Industrial Technology Faculty.

c. University of PGRI Adi Buana Surabaya Faculty of Industrial Technology, Lab. Electronics that have supported this research.

\section{REFERENCE}

[1] Dewi Ratna \& Ramiati.Pembuatan Modul Komunikasi Tanpa Kabel menggunakan Teknologi Bluetooth untuk Praktek Komunikasi Data Pada Laboratorium Telekomunikasi.Jurnal Teknik Elektro Kampus Unand Limau Manis Padang. Volume 2 No 2. Desember 2010.

[2] Djuandi Feri. 2011. Pengenalan Arduino. E-Book.www.Tobuku. Juli 2011. Diakses pada tanggal 20 April 2017.

[3] Dwi Agus Diartono. Teknologi Bluetooth untuk Layananan Internet pada Wireless Local Area Network.Jurnal Teknologi Informasi 
DINAMIK. Semarang. Vol. XIV, pp.70-

78. (Januari 2009).

[4] Evangelos Vergetis, Roch Guerin, Saswati Sarkar\& Jacob Rank.Can Bluetooth Succed as a Large-Scale Ad Hoc Networking Technolog. IEEE Journal on selected areas in communications. Vol.23. No 3. Maret 2005.

[5] Kadir Abdul. 2013. Panduan Praktis Mempelajari Aplikasi Mikrokontroler dan Pemrogramannya Menggunakan Arduino. Yogyakarta.C.V Andi Offset. 